\title{
PREVALENCE OF DEPRESSION, DEATH ANXIETY AND COPING STRATIGIES USED BY VICTIMS AND BEHOLDERS OF ARMY PUBLIC SCHOOL PESHAWAR
}

\author{
Dr. Saima Parwez ${ }^{*}$ \& Rabia Naz ${ }^{\dagger}$
}

\begin{abstract}
The study's main aim was to examine psychological effect of terrorism i.e. depression and death anxiety and the use of coping strategies i.e emotion and problem focused coping among the students of army public school. Sample comprised of 400 students age range 13 - 19 out of which 200 were victims and 200 were beholders. Through convenient sampling technique data was collected. Beck Depression scale (Aron, T, Beck, 1961), Death anxiety scale (Donald Templer, 1970) and Coping inventory (Carver,1989) were used to measure their level of depression, death anxiety and coping strategies they use. Findings indicate that scales were internally consistent and reliable. Moreover, result of the study shows that victims scored high on depression and death anxiety scale in comparison to the beholders. Victims utilized emotion focused coping techniques to tackle depression and death anxiety while beholders used problem focused coping techniques to overcome depression and death anxiety.
\end{abstract}

Keywords: Terrorism, Depression, Death anxiety, Problem Focused coping Strategies, Emotion Focused coping strategies, Victims, Beholders

\section{Introduction}

Since September 11, 2001 the globe have witness a drastic transform in the world array. Anxiety, fright, disgust feelings, hatred, and usually a profound feeling of immense insecurity occurred and conquered and

\footnotetext{
Assistant Professor, Department of Psychology, Shaheed Benazir Bhutto Women University Peshawar. Email: seemipervez82@hotmail.com

+ Student, Shaheed Benazir Bhutto Women University, Peshawar. Email:rabiashah77@ymail.com
} 
continue to dominating most of individual lives. However, there has been considerable argument and discussion regarding the incidents that occurred in that mortal time and the consequent aftermath for the whole globe. Those incident was termed as "the most horrible terrorist act, activities that were ever observed and testify due to the function of cultural activities which holds a vital place in this mass media communication period i.e TV". The influence of the pictures of two hijacking planes devastating the world trade center and their adjacent buildings, that everyone had and will impact their mind till the ending of their lives, has a foremost element in creating all the emotions that definitely all of individuals felt, at that time and certainly still feeling (Richardson,2006).

Terrorism started from America affected large parts in Asia such as India, Afghanistan and Pakistan and also many other countries. Terrorism create a situation of grief, shock, terror and horror everywhere in the world. Terrorism is not just like a shock it is described as generally the use of offensive behavior and force for the purpose of getting some goal. Internationally terrorism is described 'the illegitimate use of violent behavior and power' in opposition to citizen, land, population, or threaten a government and any part of the social or political objectives"(DSM IV,2005) When someone has suffered e.g injured or harmed as a result of someone else's actions or beliefs, or as a result of unfavorable circumstances is called victim. Terrorism have negative effect on its sufferers and victims if its good or bad both have its varying effect on its subjects (Sinclair,1987).

Couple of researches suggested that terrorism have very negative psychological affect which include many problems such as depression, various kinds of anxieties and phobias. Terrorism not only effect a single individual but it also have a negative effect on the community and society in which the individual lives. His/her life style is affected by the terrorism. The person might shows inability to trust people, failure to fully expressed their thought and feelings, decrease feelings of protection and defense, alteration in habits of eating. Increase in anger and grief, loss and hyper vigilance and guilt etc (Dumaz, 2012).

Research suggested that terrorism have a very extreme negative effect on individual. Various issues related to mental health arises due to tragic terrorist attack. Various numbers of individual get suffer from depression anxieties, sleep disorders and various kinds of drug abuse disorder. But this impact may vary from victim to victim. From victimization point of view, there are 3 spheres of individual victimization which are specified in accord with their closeness to the directly affected victims. Primarily or first order victimization is that which is faced by those directly affected by injury, loss or death. Secondary victimization is that in which people are not directly affected by injury or loss experienced by family members, relatives or friends of the first order victims and tertiary and third-order victims are those who witness victimization via media, television or radio to 
victimization or assistance and attention to victims, known as the beholder (Erez, 2006).

Depression is one of the most major impact of terrorism on individual's life. Symptoms of depression can variate from severe to moderate and mild (APA, 2015).

Depression can be caused by various factors, depending on the situation and how important it is to the person (Kessler, 2005). The loss of a relative or loved one, the loss of a employment, or the end of a relationship are difficult experiences for an individual. Feelings of grief or sadness usually increase in response to this situation. Those who experienced any loss can often depict themselves as depressed. Along with these factors, depression in humans must have risk factors that include: an individual or family with history of depression, major changes in life, grief or anxiety, and certain physiological disease and medications. Depressive disorder has developed under different circumstances depending on the situation and duration (DSM-5, 2015).

Beside depression there are other psychological problems which are also found in different population with different onset and severity in traumatized individuals. Anxiety is one of the major problem which might developed along with depression and other disorders with varying forms and types. Anxiety is fear of apprehension fear which can found in every individual but adolescents and women are at higher risk. When a person fear about death when he saw a dead body, or goes to hospital or listen about someone's death and passing through some traumatized event he is having death anxiety(APA,2014).

Death anxiety is a type of anxiety which is caused by feelings of death. Some resources describes death anxiety as a feeling of fear, anxiety, or concern when someone thinks about the procedure of death or ending (Farley, 2013). Also called thanatophobia (fear of death), death anxiety differs from necrophobia, that can be a particular fear of death and dying people and things (that is, anxiety about dead or dying, and not of one's own death or dying) (Mifflin, 2009)

When one is experiencing psychological disturbance because of any distress, trauma and disaster, the individual gain some internal power or strategies through he or she is able to cope with such psychological disorder and disturbance like praying to Allah talking to someone for assistance, and doing exercises etc. Those techniques or strategies which help a person internally to deal with the stress, anxiety, depression and other form of psychological disorders are called coping strategies.

Coping refer to the concept of thinking and actions that is used by an individual to deal with a threatening situation and stressor. Stress has a severe affect on physical and mental health. Coping strategies help an individual to deal with these stressors in a unique manner (Habraken, 2014). 
There are two types of coping: one is being able to bear stress, to function rationally well in worrying situation and get through them. The second part is recovering, getting back to normal when the stressful situation is over (Habraken, 2014). The former one is called emotion focused coping and later one is called solution focused coping strategies. These coping techniques contain maintaining a sense of humor and refining optimism or positivity where the occurrence of situation doesn't change, but your perception to perceive certain situation changes.

\section{Literature Review}

Ayesha (2016) conducted a research to investigate the "psychological effects of school shooting on children and communities" 30 families were taken into supervision from army public school massacre in 2014. The study shows that those individuals who are directly exposed to the shooting shown high rate of intrusion, avoidance, depression, different forms of anxiety and other psychological factors as compared to those who were not there at the time of attack.

A study performed by Salguero, et.al. ( 2011) to assess "the affects of purpose made terrorist attack on directly exposed victims and individuals in common population and evaluated severe depression according to the DSMV criteria". A total of 567 reports were taken in study which comprises of victims and non victims and combination of both victims and general population. Results showed that the risk of Major Depressive Disorder ranges between $20 \%$ to $30 \%$ in directly affected victims and between $4 \%$ to $10 \%$ in general population or non-victims in the early years after the attack. These risks of Major Depressive Disorder can increase by expressing more stressful situations.

Vuillermoz (2017) conducted a research to find out "the psychological impact of the 2015 terrorist attack in Paris on victims to find out the occurrence of mental health disorder. The research sample was first studied between June and September 2015 and then 1 year later between June and September in 2016. Sample included survivors and witnesses in common population security forces, police and medical staff. A questionnaire was used to measure depression and anxiety disorders. Results showed that out of 190 victims and witnesses that were interviewed, 32\% experienced depression, $43 \%$ experienced anxiety disorders among victims and 24\% experienced depression and $26 \%$ reported death anxiety among witnesses.

A study conducted by Tehreem and Naeem (2018) to find out relationship among rumination patterns, death anxiety and coping strategies among university students. Sample included 304 students out of which 163 were male and 141 were female. Rumination inventory, brief cope inventory and Templer's death anxiety inventory extended was used to evaluate the symptoms. Results showed that female students scored high on death anxiety 
scale and male students scored high on rumination scale where as male students scored high on substance used coping and avoidance copings and female student score high on religious coping strategies.

Baumeister and Muraven (1996) conducted a study on 9/11 attack. In this study they measured the affects of the 9/11 attacks on identity and death anxiety through terror management theory. The result showed that reminders of the terrorist attack produced greater death anxiety in those who were exploring their identity and less death anxiety in those who were not exploring their identity.

Gregory (2019) conducted a research on Paris attack which occurred in 2015. The research was performed to find out the symptoms of depression and death anxiety among residants. 129 people were killed at the same time and 302 were severely injured and needed emergency care in this attack. Death anxiety inventory, impact of event scale and beck's depression scale were emailed after 6 months of attack. Results showed that 76 (11.2\%) reported death anxiety 16 (2.4\%) showed symptoms of depression.

Joseph \& Bocarino et.al (2009) conducted a study to measure psychosocial predicators of terrorism, anxiety and preparedness amongst New York residents after the World trade center disaster the study was performed on 1,681 adults interviewed after 3 years of WTCD to measure the symptoms of panic attack, self-esteem, PTSD \& death anxiety. To investigate respondent's fear of death, the three question thanatophobia scale adopted from the Illness Attitude inventory was used. The result showed that participants had significant ratio of fear of death.

Yuksel et.al. (2017) performed a study in Turkey to assess the death anxiety in those individuals who had witnessed the death of their loved ones after the attack. The sample comprised of 185 individual (103 females and 82 males: age ranged from 25 to 55 years) residing in Istanbul. Personal information scale and death anxiety scale was used to collect the data. Results concluded that women tend to experience more death anxiety as compared to men, and death anxiety was greater among individuals who had witnessed the death of a close or loved one than those who did not witness such situation.

Liverant et.,al (2007) investigated the occurrence of a stress related response after the September $11^{\text {th }}$ terrorist attacks in ultimately affected college students living in Boston, Massachusetts. Anxiety was examined at intervals of approximately 2 and 4 months after the terrorist attacks. Cope inventory was used to find out the coping strategies and their initial and longer-term impact on anxiety were also investigated. Results suggested that most of the students in the research were harshly mentally affected initially by the terrorist attacks. Though, this primary affect appears to perish over time for various people. Numerous Potentially maladaptive coping techniques have been found to manifest in the projection of initial anxiety, including denial, behavioral or mental disconnection, and focusing on 
emotions and getting them out. However, it has been found that only focusing on the expression of emotion uniquely predicts long-term anxiety.

Vivian (2015) conducted a research on the affect of long-term terrorism on Palestinians to assess psychological stress and use coping strategies. The sample included 205 men and women aged 9 to 16 years. The finding shows that children with lower household incomes report higher levels of behavioral, emotional problems, and neuroticism. While emotional focused coping was significantly connected with emotional and behavioral problems, while problem focused coping was negatively linked with emotional and behavioral problems.

Baum et., al (1983) performed a research on individuals affected by technological disaster. The aim of the research was to assess coping styles that individual perform to cope with psychological problems. Age range was 18 - 25 years. Result showed that people who were near to island nuclear incidents reported depression and stress disorder and focused more on emotional focused coping i.e self blaming and those who were 100 miles away showed less psychological symptoms and focused more on problem focused coping i.e engaging themselves in some productivity.

Louck and David (2016) conducted a study to investigate the various styles of coping and their efficiency in dealing with after effects of terrorism. The sample comprised of 400 Israeli students. Results indicated that those who were directly affected showed emotional focused and integrated coping while those who witnessed the victims showed problem and adoptive coping strategies.

\section{Rationale of the Study}

On $16^{\text {th }}$ December, 2014 an oppressive massacre took place in army public school which is situated in Peshawar, the capital city of Khyber Pakhtoon Khwa province of Pakistan. The incident involved suicide bombing, mass shooting, hostility and Egyptian killing etc. Inter service public relation (ISPR) team stated that 7 suicide bombers entered the school and reached the school auditorium where students were gathered for annual day ceremony. They broke the doors of the auditorium and started firing from back side and killed many students and teachers. After 15 to 20 minutes the SSG (special service group) commandos arrived and rescued the people. The survey reported that round about 150 people were shot and lost their lives in this terrorist attack in which 132 children were included. TTP (tehreek-e-Taliban Pakistan) accepted the responsibility of the attack pointing out that this was their reprisal against Pakistan Army and operation zarb-e-azab in Waziristan. This attack gave birth to an enormous response or a chain of responses in the region. Community, political parties, religious parties, journalists and governments around the globe have condemned the terrorist attack. The whole country came and stood together. 
The main aim of the study is to find out the psychological impact of terrorism (depression and death anxiety) and the coping strategies used by victims and beholder of Army Public School.

\section{Objectives}

1. To investigate the psychological impact of terrorism on victims and beholders (students) of APS.

2. To find out the coping strategies used by the victims and beholders (students) of APS.

\section{Hypotheses}

1. Victims of APS will score high on depression and death anxiety scale as compared to beholders (students).

2. Victims of APS will use emotion focused coping strategies as compared to beholders (students).

3. Beholders (students) of APS will use problem focused coping strategies as compared to victims.

\section{Methodology}

\section{Sample}

Adolescents and adults students were taken from army public school. The sample comprised of 400 students age range 13 - 19 out of which 200 were victims and 200 were beholders. Through convenient sampling technique data was collected. Victims were considered those who were present there in the school and experienced injury. Beholders were considered those who experienced attack by hearing and seeing.

Inclusion criteria: Only victims and beholders students of Army public school attack were included in the study.

Exclusion criteria: Families of the students i.e victims and beholders were excluded from the study.

\section{Instruments}

\section{Demographic Sheet}

Demographic sheet was based on some of the following characteristics: name, gender, age, family system, religion, marital status siblings, birth order, education, qualification, victim/beholder, socio economic status.

\section{Beck's Depression Scale}

Beck's depression scale was developed by Aron T Beck (1961) this scale is further divided in three sub scales. BDI-1, BDI-SA and BDI-2. It is a 
multiple choice reporting scale and it is basically used for measuring the severity of depression. Its current version BDI-2 is made for 13 years old and above. The scale was utilized in previous studies yielded copacetic reliability $(\alpha=0.86$ for psychiatric and $\alpha=0.81$ for non-psychiatric population).

\section{Death Anxiety Scale}

Death anxiety inventory was developed by Donald Templer (1970). This scale is used to assess the anxiety, fear and apprehension related to death and events related to death. This is consisted of 2 factors scale of true false inventory and one includes 5 point Likert scales. Reliability for this scale is $(\alpha=0.76)$ which is obtained through previous researches.

\section{Cope Inventory}

The cope inventory was developed by Carver (1989). It's a sixty item inventory there is no right and no wrong answer. Five scales (4 item each) measuring aspect of problem focused coping and other five scale measured aspect of emotion focused coping strategies. There is nothing an overall score for this scale. The scale has been utilized in previous studies yielded satisfactory average reliability $(\alpha=.79)$

\section{Procedure}

After getting the permission from the principal of army public school the nature and the purpose of research was explained to her. Permission was also taken from school students and the research purpose was explained to them as well. After this the students were selected through random sampling from different classes of secondary section. The students were divided in two groups i.e. victims and beholders. Some of the data was collected from victims by sending questionnaires through mail because they were pass out. After getting the informed consent the questionnaires were distributed among both of the groups for psychological effects of terrorism. Both groups were well instructed about filling the questionnaire. After completing the first phase questionnaire i.e. depression and death anxiety inventories then coping techniques questionnaire were distributed among them and were instructed properly. They were told that there would be no negative evaluation for their responses. Respondents were appreciated for their participation in the study. 


\section{Result}

Table 1. Mean, Standard Deviation, Skewness, Kurtosis, and Alpha Coefficient of BDI, DAS and CS Scales

\begin{tabular}{|l|c|c|c|c|c|c|c|}
\hline Scales & $\begin{array}{c}\text { No. of } \\
\text { Items }\end{array}$ & $\mathbf{N}$ & Mean & SD & Skewness & $\begin{array}{c}\text { Kurtosis } \\
\text { coefficient }\end{array}$ & Alpha \\
\hline BDI & 21 & 400 & 23.08 & 15.25 & .23 & -1.5 & .96 \\
\hline DAS & 49 & 400 & 64.34 & 12.61 & -.12 & -.63 .83 & .83 \\
\hline CS & 60 & 400 & 154.98 & 13.46 & -.09 & -.69 & .76 \\
\hline
\end{tabular}

Note: $\mathrm{BDI}=$ beck depression inventory, DAS=death anxiety scale, $\mathrm{CS}=$ coping scale

Table 1 shows the values of the arithmetic mean, standard deviation, skewness, kurtosis and alpha coefficient of reliability assessment. The kurtosis and skewness values indicate that the data is normally distributed, while the alpha values indicate high reliability.

Table 2. Mean, Standard Deviation and $t$ values Scores of Students on Depression and Death Anxiety Scales ( $=400)$

\begin{tabular}{|l|c|c|c|c|c|c|c|c|c|}
\hline $\begin{array}{l}\text { Victims } \\
(\mathbf{n = 2 0 0})\end{array}$ & \multicolumn{3}{|c|}{ Beholders (n=200) } & \multicolumn{7}{c|}{$95 \%$ CI } \\
\hline & $\mathbf{M}$ & SD & M & SD & $\begin{array}{c}\mathbf{t}(\mathbf{d f}) \\
\mathbf{t}(\mathbf{8})\end{array}$ & $\mathbf{P}$ & LL & UL & Cohen's d \\
\hline Depression & 11.66 & 8.76 & 34.51 & 11.28 & 398 & 0.000 & 20.85 & 24.83 & 2.2 \\
\hline $\begin{array}{l}\text { Death } \\
\text { anxiety }\end{array}$ & 56.47 & 9.98 & 72.22 & 9.73 & 398 & 0.000 & -17.68 & -13.8 & 1.5 \\
\hline
\end{tabular}

Note: $\mathrm{CI}=$ Confidence Interval

Table 2 shows that the victims has a mean of 11.6 on depression scale and 56.47 on death anxiety scale and beholders have a mean of 34.51 and 72.22 respectively. Furthermore, the t-test value and $p$ value suggest that there is a significant difference between the means of victims and beholders. (2.2) and (1.5) Cohen's d suggest high effect size. 
Table 3. Mean, Standard Deviation and $t$ Values Scores of Students on Problem Focused Coping Scale $(\mathrm{N}=400)$

\begin{tabular}{|l|c|c|c|c|c|c|c|c|}
\hline \multicolumn{10}{|c|}{ Groups } & N & M & SD & t(df) & p & LL & UL & Cohen's d \\
\hline Victims & 200 & 60.94 & 6.66 & & & & & \\
\hline & & & & 398 & 0.000 & & -60.05 & $\begin{array}{c}- \\
57.689 .81\end{array}$ \\
\hline Beholders & 200 & 119.81 & 5.26 & & & & & \\
\hline
\end{tabular}

Note: $\mathrm{CI}=$ Confidence Interval

Table 3 shows that the victims have a mean of 60.94 and beholder has a mean of 119.81. Furthermore, the t-test value and $p$ value suggest that there is a significant difference between the means of victims and beholders. (9.8) Cohen's d suggests high effect size.

Table 4. Mean, Standard Deviation and $t$ Values Scores of Students on Emotion Focused Coping ( $\mathrm{N}=400)$

\begin{tabular}{|l|c|c|c|c|c|c|c|c|}
\hline \multicolumn{10}{|c|}{ Groups } & N & M & SD & t(df) & P & LL & UL & Cohen's d \\
\hline Victims & 200 & 81.76 & 6.12 & & & & & \\
\hline & & & & 398 & 0.000 & 36.20 & 38.64 & 6.04 \\
\hline Beholders & 200 & 44.33 & 6.26 & & & & & \\
\hline
\end{tabular}

Note: $\mathrm{CI}=$ Confidence Interval

Table 4 shows that the victims has a mean of 81.76 and beholder has a mean of 44.33.Furthermore, the t-test value and $p$ value suggest that there is a significant difference between the means of victims and beholders. (6.0) Cohen's d suggest high effect size.

\section{Discussion}

The aim of the current study is to examin the level and severity of depression and death anxiety in victims and beholders students of APS and also investigated two types of coping used by both of the groups separately.

First hypothesis of the current study is that "the victims of APS will score high on depression and death anxiety scale as compared to beholders". Students with greater or minor injury or with lost body part or with change in their physical appearance were more vulnerable to psychological disorder 
and will score greater on depression and death anxiety scale as compared to those with no injury or witness. It is because when victims look at their injury and have lost any of their relatives and loved one if experience any incidence in future would provoke them and will take them toward to psychological disorders such as depression, stress and different form of anxieties etc. In comparison to those who didn't experience the attack by seeing or hearing it personally but by listening from people and on media they had less or no psychological symptoms.

Table 2 of the current study showed that victim students score high on depression and death anxiety scale than the beholder students. The literature also suggested that people directly affected by terrorism have greater level of depression and death anxiety. Galea et.al. (2002) conducted a study in America on patients who were physically affected by terrorism. Results of the study showed that patients who are physically affected by the attack or felt any alarm against their bodily unity (hearing and seeing all that happen at the site of incident and physical nearness to that site) had a major risk of developing major depressive disorders and different forms of anxieties.

Second hypothesis of the study suggested that "victims of APS will use emotion coping strategies as compared to beholders students". Victim students i.e who had any injury or lost any loved one in attack will not be emotionally stable as compared to beholders because they didn't have such experience of injury or loosing loved one.

Victim students when heard of any other similar incidence will start venting, they would leave that place and they would deny the loss of loved one and will totally leave everything on the divine reality. While the beholders students will effectively cope with such situation. They will talk about the situation with other people, they will seek guidance and counseling from friends and family and work on the solution of the problem.

According to the results of the present study from table no 3 showed that victims students used emotion coping strategies as compared to beholders students. Literature also suggested individuals who were directly affected by terrorism and having some injury used emotional focused coping strategies while those who witnessed the incident use problem focused coping strategies. Louck and David (2017) investigated various coping styles and their efficiency in dealing with terrorism. Sample comprised of 2 strata: directly exposed to terrorism and participants indirectly exposed to terrorism. Brief symptoms inventory and brief cope inventory (Carver, 1997) were used in the study. Results showed that directly exposed group showed significantly high scores on self-destruction and venting (emotion focused coping) whereby indirectly exposed group scores high on humor and acceptance (problem focused coping).

Third hypothesis suggested that "beholders students of APS will use problem focused coping strategies as compared to victims students." It is because beholders students who have no any injury or didn't lose any loved 
one in the incident will be have enough emotional stability as compared to victims, they would not become emotional when they hear about any similar incidence. They would have less vulnerability as compared to victims. They would accept the reality of facing and experiencing any incidence. They would affectively cope with the situation as compared to victims. The result of table 4 of the current studies showed that beholders students will use problem focused coping strategies as compared to victim students. Literature also suggested that individuals who were not directly affected by terrorism will use problem focused coping strategies. Marcum and Meislender (2004) examine the after effects of terrorism and coping strategies in victims of 9/11.A mailed survey of 814 active participants were obtained. Results showed that $76 \%$ of participants rated high on stress and anxiety scale. And those who directly witnessed terrorism were engaged in using problem focused coping while those who were indirectly affected by experiencing it through media were engaged in emotion focused coping strategies.

\section{Conclusion}

The present study contributed to the literature by investigating the psychological effects of terrorism and the relationship between coping strategies and psychological disorders i.e depression and death anxiety. A significant result was found that two types of coping strategies i.e problem focused coping strategies helps beholders in reducing their depression and death anxiety while victims used emotion coping strategies in combating their psychological effects of terrorist attack.

As the main objective of the study was approved that terrorism result in its long term psychological effects, it is evident from the result that terrorism do have long term effects on those individuals who are effected directly or indirectly it is because the world is facing major issue of fighting with terrorism. Every day any incident would occurred and it has left its impact in people's mind. They have lost their homes, their properties, their earnings and their loved ones. When they face any new incident it reminded them of their own loss so they become anxious and depressed. In response to the life threatening effects of terrorism every individual is blessed with some internal capacity to cope with these psychological effects such as defense mechanism and coping techniques.

If the results of the current study were applied in the field, people will be able to recognize their coping strategies that is positive disengagement, mental growth, religious beliefs talking to others and taking guidance, venting their emotions and engaging themselves in some productive work confronting and seeking aid from professional will help them effectively cope with the ongoing consequences of terrorism which is uncontrollable. The present study provided that students who are positive for psychological 
effects need to be targeted to counseling either to media or through their institutions.

\section{Limitations}

Despite efforts to make a study limitation free, in the field of social sciences it can hardly be the case. The current study included the following shortcomings:

1. Data was only collected from the male students belonging to the specific classes i.e. grade 8-12. Which is not representative of the students studying in other classes and teachers working there and families. In future sample should be more varied in term of standards and profession.

2. To make a study more objective and precise both genders should be included in the study to compare the differences between psychological effects and coping strategies in them. Each gender has their own capability and coping mechanism to deal with terrorism's effects.

3. There was less deviation in the ages of the selected individuals, which yields that difference. Psychological effects and coping was not assessed at different ages. Age might have been one of the significant determinant of coping.

\section{Suggestion}

Similarly some precautionary measures can be suggested to reduce psychological aftermath and enhance coping in students like:

1. Psychological consequences of terrorism can be reduced by introducing professionals i.e psychologist and counseling services in institutions.

2. Counseling awareness should be given to families of the victimized students.

\section{References}

American Psychiatric Association. (2013). Diagnostic and Statistical Manual of Mental Disorders (5th ed.).Washington, DC.doi:https://doi.org/ 10.1136/bmj.f3591.

Baum, A., R. Fleming, and J.E. Singer (1982) "Stress at Three Mile Island: applying psychological impact analysis," in L. Bickman (ed.) Applied Social Psychology Annual. Beverly Hills, CA: Sage.

Baumeister, R.F., \& Muraven, M. (1996). Identity as adaptation to social, cultural, and historical context. Journal of Adolescence, 19, 405-416.

Cohen-Louck, K., \& Ben-David, S. (2016, April 7). Coping With Terrorism: Coping Types and Effectiveness. International Journal of Stress Management. http://dx.doi.org/10.1037/str0000016. 
Diagnostic and Statistical Manual of Mental Disorders.(2013) DSM Library (5th ed.). American Psychiatric Association. doi:10.1176/9780890425596.5

Dumaz, B. (2012) Evaluating Counterterrorism Performance. A Comparative Study. London/New York: Routledge.

Erez, E. (2006). "Protracted War, Terrorism and Mass Victimization: Exploring Victimological/Criminological Concepts and Theories to Address Victimization in Israel." In Uwe Ewald and Ksenija Turkovic(eds.), Large- Scale Victimisation as a Potential Source of Terrorist Activities. Amsterdam: IOS Press, pp. 89-103.

Farley G. (2013). Death anxiety. National Health Service UK.

Galea, S., Ahern, J., Resnick, H., Kilpatrick, D., Bucuvalas, M., Gold, J., \& Vlahov, D. (2002). Psychological Sequelae of the September 11 Terrorist Attacks in New York City. New England Journal of Medicine, 346(13), 982-987. 45.

Gurr, T. (1970). Why Men Rebel. Princeton University Press: Princeton.

Habrakenh, H. (2014). Searching for the structure of coping: A Review and critique of category systems for classifying ways of coping. Psychological Bulletin, 129(2), 216-269.

Joseph A. Boscarino. Richard E. Adams.Charles R. Figley. Sandro Galea \& Edna B. Foa. (2009). Fear of Terrorism and Preparedness in New York City 2 Years After the Attacks: Implications for Disaster Planning and Research. .J Public Health Manag. Pract.12(6): 505-513.

Jules Gregory, Jean de Lepinau, Ariane de Buyer \& Nicolas Delanoy. (2019). The impact of the Paris terrorist attacks on the mental health of resident physicians. Department of Cancer Medicine, Gustave Roussy Cancer Campus, Université Paris-Saclay.

Kessler, R.C. (2005). Lifetime Prevalence and Age-of-Onset Distributions of DSM-IV Disorders in the National Comorbidity Survey Replication. Arch Gen Psychiatry journal, 62(6), 38-48. Retrievedfromhttp://archpsyc.jamanetwork.com/article. aspx?articleid=2 08678.

Liverant, G.I., Hofmann, S.G., \& Litz, B.T. (2004). Coping and anxiety in college students after the September 11th terrorist attacks. Anxiety, Stress, Coping, 17 (2), 127.

Richardson, L. Murray, J. (2006). What terrorists want? Understanding the enemy. New York: Cambridge University.

Salguero. J, M. (2011) Emotional intelligence and depression after the M-11 terrorist attacks in Madrid. PhD Thesis. Completeness University of Madrid, Basic Psychology Department. SBS Television (2012) World News. Retrieved from http://www.ricardogoncalves. 50 com.au

Sinclair, S.J., \& LoCicero, A. (1987). Fearing future terrorism: Development, validation, and psychometric testing of the Terrorism 
Catastrophizing Scale (TCS). Traumatology, 13(4), 75-90. doi:10.1177/1534765607309962

Tahreem. K. (2016). Muslim spirituality, religious coping, and reactions to terrorism among Pakistani University Students. Journal of Religious Health, 55(6), 2086- 2098. doi:10.1007/s10943-016-0263-2.

Vivian Khamis. (2015). Post-traumatic stress disorder among school age Palestinian children. Child Abuse \& Neglect 29(1):81 https://doi.org/10.1016/j.chiabu.2004.06.013

Vuillermoz. M, A. (2017) Review of somatic symptoms in post-traumatic stress disorder. Int Rev Psychiatry.25(1):86-9.

Yukay Yüksel, M., Güneş, F., \& Akdağ, C. (2017). Investigation of the death anxiety and meaning in life level among middle-aged adults. Spiritual Psychology and Counseling, 2, 165-181. http://dx.doi.org/10.12738/spc.2017.2.0024 